\title{
Systematic Reviews in Public Health
}

Paudel D ${ }^{1}$

${ }^{1} \mathrm{BPH}, \mathrm{MPH}, \mathrm{MPA}$

In the era of evidence-based public health, systematic reviews are becoming more and more popular and being used more often both as a method of study and as a source of evidence for program and policy development. Thus, public health students and professionals should know and understand the concept, process and value of systematic reviews on different public health topics. Due to higher level of evidence ranking, findings from the systematic reviews are being used more often for policy and program development. Initially, systematic reviews only included findings from the randomized controlled trials, but now it also includes highquality quasi-experimental studies as randomized control trials are not feasible in all public health topics. Primary purpose of this paper is to orient public health students and professionals about systematic review and thus presented in frequently asked questions and response format.

\section{What is a systematic review?}

A systematic review is a high-level overview of primary research on a particular research question that tries to identify, select, synthesize and appraise all high quality research evidence relevant to that question in order to answer it. (1) The purpose of a systematic review is to sum up the best available research on a specific question. This is done by synthesizing the results of several studies using metaanalysis. (2) Meta-analysis is the statistical analysis of the data/results from studies included in a systematic review to produce an overall, pooled result. (3)

\section{Why systematic reviews?}

A systematic review answers the same research question and that conforms to set criteria based on the review of the methods and results of all individual studies; it, therefore, provides higher level of evidence than from a primary study. (3)

Though hierarchy of evidence is a matter of debate (4), evidence from the systematic reviews are considered "superior " compared to those from the randomized control trial, cohort study, case-control study, cross-sectional study and case study. Table 1 shows the strengths of evidence from different studies by the types of the research questions.

Table 1: Hierarchy of evidence by type of research questions (4)

\begin{tabular}{|c|c|c|c|c|c|c|c|c|}
\hline Bratrotratur & Tritultit & Entin & $\begin{array}{l}\text { Ent } \\
+1+1 \\
n+11\end{array}$ & $\frac{\text { Entra }}{1+1+1}$ & RAI & $\frac{7+1}{4+1}=$ & 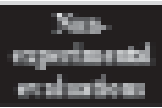 & 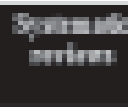 \\
\hline 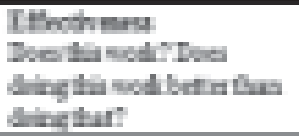 & & & & 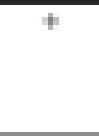 & 반 & ti & & 4ht \\
\hline 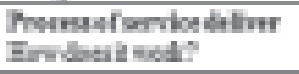 & 4 & 4 & & & & & 4 & 414 \\
\hline $\begin{array}{l}\text { Briner } \\
\text { Britrater }\end{array}$ & +4 & + & & & & & & +4 \\
\hline 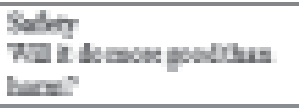 & 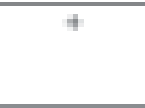 & & 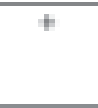 & + & $=1$ & $F$ & + & +11 \\
\hline 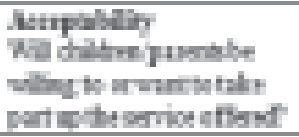 & + & & & & $=$ & + & + & $+\mathrm{HH}$ \\
\hline 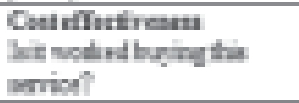 & & & & & + & & & $+t+4$ \\
\hline 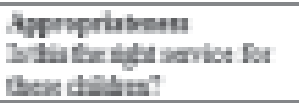 & $H$ & 1 & & & & & & 1 \\
\hline 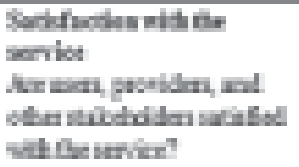 & 11 & 11 & 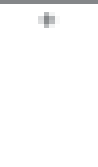 & 1 & & & & $\pi$ \\
\hline
\end{tabular}

CORRESPONDENCE: Deepak Paudel, BPH, MPH, MPA, Email: paudeld@gmail.com 


\section{What are the groups supporting systematic reviews?}

The Cochrane Collaboration (1) is an international network of more than 28,000 dedicated people from over 100 countries. The Cochrane collaborators work together to help healthcare providers, policy-makers, patients, their advocates and carers, make well-informed decisions about health care, by preparing, updating, and promoting the accessibility of Cochrane Reviews. More than 5,000 systematic reviews are available online in the The Cochrane Library: www.thecochranelibrary.com. The library provides one-click free access to the resources in low income countries. The Cochrane Collaboration also developed and regularly updates the Handbook for Systematic Reviews of Interventions (www.cochrane-handbook.org) that provides guidance to authors for the preparation of Cochrane Intervention reviews.

The Campbell Collaboration (2) is an international research network that produces systematic reviews of the effects of social interventions. Campbell is based on voluntary cooperation among researchers of a variety of backgrounds. The Campbell Collaboration (C2) helps people make wellinformed decisions by preparing, maintaining and disseminating systematic reviews in education, crime and justice, and social welfare. Systematic reviews conducted from the Campbell Collaboration are available at the Campbell online library: http://www.campbellcollaboration.org/ library.php

The Evidence for Policy and Practice Information and Coordinating Centre (EPPI-Centre) (5) is part of the Social Science Research Unit at the Institute of Education, University of London. The EPPI-Centre has been carrying out systematic reviews and developing review methods in social science and public policy. The centre is dedicated to making reliable research findings accessible to the people who need them, whether they are making policy, practice or personal decisions. The centre has a large number of systematic reviews in the fields of education, health promotion and public health, as well as social welfare and international development. The EPPI-Centre (www.eppi.ioe.ac.uk) provides online EPPIReviewer Software to manage different steps of systematic reviews and the Evidence-library to search systematic reviews.

International Initiatives for Impact Evaluations (3ie) (6) is supported by UK Department for International Development (DFID), Bill and Melinda Gates Foundation and other donors to funds impact evaluations and systematic reviews to generate evidence on what works in development programs and why. These evidences are used to inform policy and to improve the lives of poor people. Alike others, 3ie provides a database of systematic reviews (www.3ieimpact.org/en/ evidence/systematic-reviews) and provide funds to examine the existing evidence on a particular intervention or program in low and middle income countries, drawing also on evidence from developed countries when pertinent.

There are other centers /groups involved in systematic reviews of their interest, and information from them can be obtained from their sites, such as Collaboration for Environmental Evidence and Center for Evidence Based Crime Policy. (7)

\section{How to carry out systematic reviews?}

Systematic review involves a structured, rigorous, and objective approach to provide a critical synthesis of the available evidence in a particular field. (8)The process generally involves multiple steps including defining research question, developing a protocol, searching and selecting studies, examining included studies (including data extraction

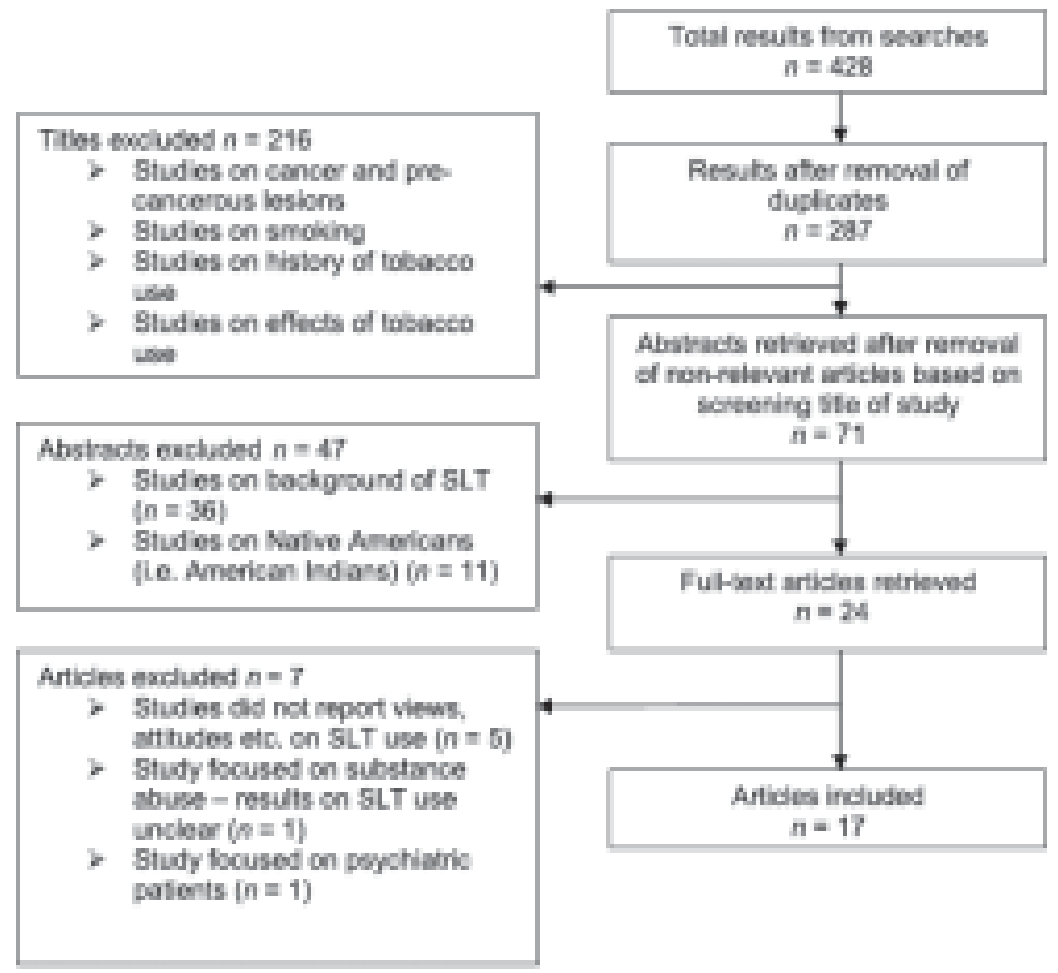

Figure 1: Example of a typical flow chart of a systematic review (10) 
and quality appraisal), undertaking synthesis and presenting results. The whole process takes couple of months and requires individuals with multiple skills set, just like in primary studies.

The Cochrane handbook (9) suggests following steps in doing systematic reviews of interventions:

1. Defining the review question and developing criteria for including studies

2. Searching for studies

3. Selecting studies and collecting data

4. Assessing risk of bias in included studies

5. Analyzing data and undertaking meta-analyses

6. Addressing reporting biases

7. Presenting results and 'Summary of findings' tables

8. Interpreting results and drawing conclusions

A systematic review require extensive and comprehensive search of primary research from studies, typically from electronic database, filtrations of research papers based on pre-set inclusion and exclusion criteria, data extraction and meta-analysis. Figure 1 shows the typical example of a systematic review flow chart.

What is the difference between systematic review, literature review and meta-analysis?

Systematic review is possible and appropriate where there are multiple primary studies available for review. However, some systematic reviews were concluded stating that there is not any primary research that fulfills the inclusion criteria of the systematic review. In other cases, hundreds of studies were included in the meta-analysis for a systematic review. Systematic review is not just the literature review or metaanalysis, and thus should be carefully differentiated whileusing these terms. Literature review is mainly descriptive, doesn't involve a systematic search of the literature, and thereby often focuses on a subset of studies in an area chosen based on availability or author selection, and thus can often have selection bias. (11) Meta-analysis is the statistical analysis to generate pooled results for the data/results from the studies included in a systematic review; however can be used separately than in a systematic review. Systematic reviews, as the name implies, typically involve a detailed and comprehensive plan and search strategy derived a priori, with the goal of reducing bias by identifying, appraising, and synthesizing all relevant studies on a particular topic. (11)

\section{What are some examples of systematic reviews in Nepal?}

Typically, systematic reviews are not country specific as they require multiple primary research studies with comparable methodology and common outcome. Systematic review covers evidence from all eligible primary research studies on the specific topic of interest from electronic database and library search available at the time of review.
However, many systematic reviews $(10,12,13)$ included Nepal based primary research in the systematic reviews.

\section{Acknowledgements:}

I would like to thank Tracey Lynn Perez Koehlmoos from the ICDDR,B Center for Systematic Reviews for the resources provided during "Capacity Building for Systematic Review Workshop" in Kathmandu, Nepal.

\section{References:}

1. The Cochrane Collaboration. http://www.cochrane.org/. Secondary http://www.cochrane.org/.

2. The Campbell Collaboration. http://www. campbellcollaboration.org. Secondary http:// www.campbellcollaboration.org.

3. Bruce N, Pope D, Stanistreet D. Systematic reviews and metaanalysis. Quantitative Methods for Health Research. London, UK: John Wiley \& Sons Ltd, 2008

4. Petticrew M, Roberts H. Evidence, hierarchies, and typologies: horses for courses. Journal of epidemiology and community health $2003 ; \mathbf{5 7}(7): 527-9$

5. The EPPI-Centre. http://eppi.ioe.ac.uk. Secondary http:// eppi.ioe.ac.uk.

6. International Initiatives for Impact Evaluations. http:// www.3ieimpact.org. Secondary http://www.3ieimpact.org.

7. ICDDRB Centre for Systematic Review. Overview of Systematic Review Collaborators, PowerPoint Presentation, available from http://www.icddrb.org/what-we-do/health-programmes/healthand-family-planning-systems/centre-for-systematic-review-csr/ training. Secondary Overview of Systematic Review Collaborators, PowerPoint Presentation, available from http:/ /www.icddrb.org/what-we-do/health-programmes/health-andfamily-planning-systems/centre-for-systematic-review-csr/ training 2012

8. Teijlingen Ev, Simkhada B, Ireland J, Simkhada, Bruce J. Evidence-based health care in Nepal: The importance of systematic reviews. Nepal Journal of Epidemiology 2011;1(4):114-18

9. Higgins J, Green S, editors. Cochrane Handbook for Systematic Reviews of Interventions Version 5.1.0 [updated March 2011]: Available from www.cochrane-handbook.org., 2011.

10. Kakde S, Bhopal RS, Jones CM. A systematic review on the social context of smokeless tobacco use in the South Asian population: Implications for public health. Public health 2012;126(8):635-45 doi: 10.1016/ j.puhe.2012.05.002[published Online First: Epub Date]|

11. Uman LS. Systematic reviews and meta-analyses. Journal of the Canadian Academy of Child and Adolescent Psychiatry = Journal de l'Academie canadienne de psychiatrie de l'enfant et de 1'adolescent 2011;20(1):57-9

12. Lassi ZS, Haider BA, Bhutta ZA. Community-based intervention packages for reducing maternal and neonatal morbidity and mortality and improving neonatal outcomes. Cochrane database of systematic reviews 2010(11):CD007754 doi: 10.1002/ 14651858.CD007754.pub2[published Online First: Epub Date]|

13. Gogia S, Ramji S, Gupta P, et al. Community based newborn care: a systematic review and metaanalysis of evidence: UNICEF-PHFI series on newborn and child health, India. Indian pediatrics $2011 ; \mathbf{4 8}(7): 537-46$ 